\title{
COVID-19: What Comes Next for IRs
}

\author{
Klaus A. Hausegger ${ }^{1}$
}

Published online: 27 April 2020

(C) Springer Science+Business Media, LLC, part of Springer Nature and the Cardiovascular and Interventional Radiological Society of Europe (CIRSE) 2020

The current COVID-19 pandemic is confronting healthcare systems worldwide with many logistical and infrastructural challenges; not the least of these is the risk to healthcare professionals themselves. Since interventional radiology (IR) is an integral part of every modern hospital structure, we as interventional radiologists need to have a clear understanding of how we can provide an adequate IR service for COVID-19 infected or potentially infected patients and how we can protect ourselves and our staff from infection in the most effective way.

In this special section on COVID-19, we want to give our readers the opportunity to benefit from the experiences of departments which have already been confronted with this pandemic. In a more general article, Gao-Jung Teng, our regional Editor for China, describes how the directors of the Nanjing Hospital in China reacted to the expected Corona pandemic in terms of management of the whole hospital setup, how they handled infection control, patient segregation, appropriate deployment of staff, etc. The other articles specifically describe the adjusted workflow in an IR department under COVID-19 circumstances and how this has been accomplished in Singapore, Spain and in Italy. There may be some minor differences, but the basic principles are the same.

Under these extraordinary circumstances, it is vital to share experiences and knowledge worldwide to ensure we learn lessons and achieve the best outcome for patients without compromising staff safety. Therefore, we hope that these articles in this special section can help our readers to get their IR structures well prepared for treating patients who are suffering from COVID-19 infections.

Publisher's Note Springer Nature remains neutral with regard to jurisdictional claims in published maps and institutional affiliations.

Klaus A. Hausegger

CVIR.Hausegger@kabeg.at

1 Department of Diagnostic and Interventional Radiology,

Klagenfurt State Hospital, Klagenfurt, Austria 